This item was submitted to Loughborough's Research Repository by the author.

Items in Figshare are protected by copyright, with all rights reserved, unless otherwise indicated.

\title{
Development, validity and reliability testing of the East Midlands Evaluation Tool (EMET) for measuring impacts on trainees' confidence and competence following end of life care training
}

\section{PLEASE CITE THE PUBLISHED VERSION}

https://doi.org/10.1136/bmjspcare-2016-001100

\section{PUBLISHER}

(C) BMJ Publishing Group

\section{VERSION}

AM (Accepted Manuscript)

\section{PUBLISHER STATEMENT}

This work is made available according to the conditions of the Creative Commons Attribution-NonCommercialNoDerivatives 4.0 International (CC BY-NC-ND 4.0) licence. Full details of this licence are available at: https://creativecommons.org/licenses/by-nc-nd/4.0/

\section{LICENCE}

CC BY-NC-ND 4.0

\section{REPOSITORY RECORD}

Whittaker, Becky, Ruth Parry, Lydia Bird, S. Watson, and Christina Faull. 2019. "Development, Validity and Reliability Testing of the East Midlands Evaluation Tool (EMET) for Measuring Impacts on Trainees' Confidence and Competence Following End of Life Care Training". figshare. https://hdl.handle.net/2134/32672. 
DEVELOPMENT, VALIDITY AND RELIABILITY TESTING OF THE EAST MIDLANDS EVALUATION TOOL (EMET) FOR MEASURING IMPACTS ON TRAINEES CONFIDENCE AND COMPETENCE FOLLOWING END OF LIFE CARE TRAINING

Whittaker B, Parry R, Bird L, Watson S, Faull C

On behalf of the EMET project team

Corresponding Author

Becky Whittaker

Assistant Professor

School of Health Sciences

The University of Nottingham

Room B58, Medical School

Queens Medical Centre

Derby Road

Nottingham NG7 2HA

Tel.+44115 8230875

Email becky.whittaker@nottingham.ac.uk

\section{Co-authors}

Ruth Parry, Principal Research Fellow, Sue Ryder Care Centre for the study of Supportive, Palliative and End of Life Care, School Health Sciences, University of Nottingham, Nottingham, UK

Lydia Bird, Senior Research Fellow, Division of Primary Care, School of Medicine, University of Nottingham, Nottingham, UK

Sharan Watson, Post Graduate Lecturer, University of Derby, UK

Christina Faull, Consultant Palliative Medicine, LOROS Hospice, Leicester, UK

Keywords

End of life care training; competence; evaluation; questionnaire; self-assessment/report

Word count

3374 


\section{ABSTRACT (word count 250)}

\section{Objectives}

To develop, test and validate a versatile questionnaire, East Midlands Evaluation Tool (EMET), for measuring effects of end of life care training events on trainees' self-reported confidence and competence.

\section{Methods}

A paper based questionnaire was designed on the basis of the English Department of Health's core competencies for end of life care, with sections for completion pre-training, immediately posttraining, and also for longer term follow-up.

Preliminary versions were field-tested at 55 training events delivered by 13 organisations to 1793 trainees working in diverse health and social care backgrounds. Iterative rounds of development aimed to maximise relevance to events and trainees. Internal consistency was assessed by calculating inter-item correlations on questionnaire responses during field-testing. Content validity was assessed via qualitative content analysis of (a) responses to questionnaires completed by fieldtester trainers, and (b) field-notes from a workshop with a separate cohort of experienced trainers. Test-retest reliability was assessed via repeat administration to a cohort of student nurses.

\section{Results}

The EMET comprises 27 items with Likert-scaled responses supplemented with questions seeking free-text responses. It measures changes in self-assessed confidence and competence on five subscales: communication skills; assessment and care planning; symptom management; advance care planning; overarching values and knowledge. Test-retest reliability was found to be good, as was internal consistency: the questions successfully assess different aspects of the same underlying concept.

\section{Conclusions}

The EMET provides a time-efficient, reliable and flexible means of evaluating effects of training on self-reported confidence and competence in the key elements of end of life care. 


\section{INTRODUCTION}

Policies in the UK, $[1,2]$ and internationally, $[3,4]$ strongly endorse staff training as a means to increase both specialist and non-specialist health and social care workers' competence in end of life care delivery. In England in recent years, there has been a proliferation of training events that vary widely in length, modality, trainees and content.[5] These training events range from half to multiple days, and trainees span a broad spectrum of occupational and professional backgrounds, grades, settings and patient groups. Many events are multi-professional.

The gold-standard means of assessing the impact of training is to perform before and after workplace observations of staff and patients interacting.[6, 7] However this can be highly timeconsuming, whilst evaluation via self-report is far more feasible and economical. Therefore, even though it is known that self-reported confidence and competence do not straightforwardly reflect actual workplace behaviour change, $[8,9]$ self-report often represents the best available option when resources do not stretch to workplace observations. A systematic review examined existing self-report tools relevant to assessing end of life care training,[10] and found that most are poorly validated and narrow in scope, and that they largely focus on physical aspects of symptom management. Some tools are also narrowly focused on single professional groupings.[11] This means that current tools have limited usefulness in the current environment where, as we noted, end of life care training events are very diverse. Furthermore, evaluations of effects of end of life care education and training interventions published over the last decade all report designing and using individual, project-specific evaluation questionnaires.[12-15] This adds to the evidence that we lack, and need, established, validated, and broadly relevant tools.

Our questionnaire, referred to as a 'tool' is designed to offer a rapid and feasible means to evaluate end of life care training events by measuring changes in trainees' self-reported confidence and competence. By confidence, we mean the self-awareness of having the competence to complete a task or reach a goal.[16] By competence, we mean having the appropriate skills and behaviours to undertake specific activities.[17] Fortunately, a clear and government-endorsed articulation of core competencies for end of life care exists,[18, 19] see Table 1. 
TABLE 1: The English Department of Health Core Competences for End of Life Care [19]

\begin{tabular}{|l|l|}
\hline & Common Core Competency \\
\hline 1 & $\begin{array}{l}\text { Communication skills: engaging effectively with family and patient/resident in } \\
\text { discussions about dying and death }\end{array}$ \\
\hline 2 & $\begin{array}{l}\text { Assessment and care planning: holistically assess, develop, implement and review a } \\
\text { plan of care involving the family and patient/resident as appropriate }\end{array}$ \\
\hline 3 & $\begin{array}{l}\text { Symptom Management: provide quality symptom management including } \\
\text { maintaining comfort and wellbeing }\end{array}$ \\
\hline 4 & $\begin{array}{l}\text { Advance Care Planning (ACP): engage in discussions with family and patient/resident } \\
\text { and show awareness of legal and ethical issues around the ACP process }\end{array}$ \\
\hline 5 & $\begin{array}{l}\text { Overarching values and knowledge: awareness of own values, knowledge and on- } \\
\text { going professional development in supporting self and others in end of life care }\end{array}$ \\
\hline
\end{tabular}

These competencies were developed with the aim of providing a sound framework for the commissioning and design of training programmes recommended in English end of life care policy.[5] They also provide a useful basis for evaluating events.

\section{METHODS}

\section{Tool development}

The East Midlands Evaluation Tool (and hereon as EMET), was initially designed by authors BW and CF and project team member DB on the basis of the English core competences for end of life care,[19] see Table 1. It was then refined and developed by the EMET project team (see acknowledgements) over a four year period through 5 iterative rounds of development. Whilst in practice, all sections of the tool are designed to be used in non-anonymised form, during testing, all completed questionnaires were anonymised by ensuring each trainee only wrote their unique identifying code on the questionnaire.

Initial design of the tool entailed:

- A literature search and review which found that there were no validated tools available for evaluating the impact of end of life care learning events across a range of roles and care settings. $[10,11]$

- Discussions within a project team that included clinical and educational experts in end of life care.[20-22]

- Translation of the overarching statements of competencies in the Department of Health's framework, $[18,19]$ into questionnaire items grouped into the same subdomains. This entailed translating broad characteristics into more specific skills, practices or activities. For 
example, the statement of communication competence: "Develop and maintain communication with people about difficult and complex matters or situations related to end of life care" was reformulated to: "I feel confident to talk with a dying person about issues surrounding their death"

The resulting tool comprised of a total of 27 statements to which trainees were asked to respond via Likert-scaled responses. This was supplemented by (a) narrative questions seeking free-text responses to gain trainee views on whether, and how, the training had changed their confidence and competence in the delivery of end of life care.

The next stage of development involved field-testing the tool by administering it across a wide range of training events delivered by a total of 13 different organisations. We used the East Midlands Strategic Health Authority and personal networks of the project team to recruit trainers willing to use the tool to evaluate their training events. Thirteen organisations used the tool in 55 different training events involving 1793 trainees. Almost three quarters (71\%) of the training events involved mixed cohorts of both registered and non-registered employees from various occupational backgrounds and care settings. Events and trainees are described in Table 2.

TABLE 2: Training events and trainees using the tool

\begin{tabular}{|c|c|c|c|}
\hline $\begin{array}{l}\text { Delivering } \\
\text { organisation field } \\
\text { testing the tool } \\
(n=13)\end{array}$ & $\begin{array}{l}\text { Length of } \\
\text { training } \\
\text { event }\end{array}$ & $\begin{array}{l}\text { Occupation of participants completing } \\
\text { the tool }\end{array}$ & $\begin{array}{l}\text { Number of } \\
\text { trainees } \\
\text { completing the } \\
\text { tool ( } n=1793 \text { ) }\end{array}$ \\
\hline $\begin{array}{l}\text { Higher Education } \\
\text { Institution } \\
(n=3)\end{array}$ & $\begin{array}{l}3 \text { days }-8 \\
\text { weeks }\end{array}$ & $\begin{array}{l}\text { registered nurses } \\
\text { social workers } \\
\text { physiotherapists } \\
\text { non-registered carers } \\
\text { care home managers } \\
\text { chaplains } \\
\text { student nurses } \\
\text { end of life care trainers }\end{array}$ & $\begin{array}{l}53 \\
45 \\
55 \\
31 \\
45 \\
10 \\
17 \\
36\end{array}$ \\
\hline $\begin{array}{l}\text { Hospice education } \\
\text { programme } \\
(n=5)\end{array}$ & 1-6 days & $\begin{array}{l}\text { out of hours GPs } \\
\text { registered nurses } \\
\text { non-registered carers }\end{array}$ & $\begin{array}{l}37 \\
410 \\
421\end{array}$ \\
\hline $\begin{array}{l}\text { Community NHS } \\
\text { Trust } \\
(n=2)\end{array}$ & 1 day & registered nurses, non- registered carers & $\begin{array}{l}201 \\
31\end{array}$ \\
\hline $\begin{array}{l}\text { NHS regional } \\
\text { ambulance service } \\
(n=1)\end{array}$ & 1 & ambulance practitioners & 87 \\
\hline
\end{tabular}




\begin{tabular}{|c|c|c|c|}
\hline $\begin{array}{l}\text { Acute NHS Trust } \\
(n=1)\end{array}$ & 1 & registered nurses (induction programme) & 147 \\
\hline Voluntary education & 1-2 days & registered nurses & 81 \\
\hline provider for health & & non-registered carers & 46 \\
\hline care professionals & & doctors & 24 \\
\hline
\end{tabular}

occupation not identified

Trainers returned the questionnaires completed by each trainee to the EMET project team.

Additionally, all trainers administering the tool during field-testing were asked to complete a brief 'Feedback Questionnaire' which sought both Likert-scaled and free text responses on the ease of use of the tool, whether it reflected the aims of their own event(s), and whether they thought any items needed adding, altering or removing. This questionnaire is provided in Supplementary File 1.

At this stage the tool was modified in the light of:

- trainers' feedback; both informally and via a questionnaire survey.

- a review of trainee responses to both the closed statements and narrative questions.

- the needs and requests of trainers and organisations delivering the courses.

- new policy initiatives - in particular the UK's National Institute on Health and Care Excellence (NICE) guidance focused upon recognising dying, avoiding inappropriate hospital admissions and initiating conversations about end of life.[23]

The modifications entailed rewording some questionnaire statements and narrative questions so as to improve their applicability across a wide range of trainees and events. For instance, the initial version of the EMET referred to the care of patients, this was changed so as to replace reference to 'patients' with reference to 'people in my care'. Other modifications made questionnaire items better reflect the competencies being measured by the Likert-scaled items and reported in the narrative questions. For example, some trainees noted the importance of listening to patients, and as a result the initial wording of one item: "I feel confident to talk with a dying patient about issues surrounding their death" was modified to: "I feel confident to listen to and talk with a dying person about issues surrounding their death".

\section{Reliability}

Two domains were tested: test-retest reliability and internal consistency.

Test-retest reliability 
Reliable tools produce the same score or measurement each time they are used if there has been no change to the features being measured.[24, 25] Thus, if the trainee's self-assessed confidence and competence remains constant, there should be no change in their score on the EMET. Conversely, any change in their score should be due to a change in self-assessed confidence and competence. We examined the degree to which the tool yielded the same results from one administration to the next under the same conditions using a convenience sample of student nurses from a single year group in the Division of Nursing at the University of Nottingham. The students completed the EMET's 27 Likert-scaled items on two occasions one week apart. During that week, they received no end of life care specific teaching and were not exposed to clinical situations in which end of life care would have been observed. The correlation between the two scores was tested using a power calculation of $15 \%$ deviation. Scores were tested using a Pearson $r$ test.[26]

\section{Internal consistency}

A reliable multi-item tool will give consistent results when different aspects of the same underlying concept are measured by more than one item.[27] During field-testing, we examined the internal consistency of results across different multi-item sets of questions. Inter-item correlations were calculated for each of the five core competence subscales using Cronbach's $\alpha$ values.[26]

\section{Validity}

Validity refers to whether a tool is measuring what it is designed and claimed to measure. We examined content validity; whether the domains examined by the tool were appropriate, important and sufficient to its purposes.[25] Content validity is examined through consultation with interested parties rather than via statistical methods. Accordingly, we conducted two separate structured consultations. One of these entailed completion and analysis of trainer feedback questionnaires during field testing as described above (see Supplementary File 1 and Table 2). We collated frequencies for the responses to the Likert-scaled statements and analysed responses to the narrative questions via inductive qualitative content analysis.[28] Second, we designed and ran a three part structured workshop during the 2012 conference of the UK National Association of Palliative Care Educators (NAPCE). The workshop began with experienced end of life care trainers testing the tool by completing its pre-training section. Next, they participated in facilitated small group discussions designed to consider positive and negative aspects of the tool. Finally, a large group discussion brought together the views of the small groups. Contemporaneous field-notes were made by authors BW and SW. These were collated and analysed via inductive qualitative 
content analysis.[28] The process of tool development over a four year period is illustrated in figure 1.

FIGURE 1: Process of tool development

[Fig 1 to be inserted here]

RESULTS

\section{Tool Development}

The resulting questionnaire 'tool' is available as Supplementary File 2. It comprises three sections: Pre-training section "Tool A"

This is completed immediately before the training begins - usually at the event venue itself, but it can be sent to each trainee before the event. It gathers brief background information on the trainee's work setting, professional qualifications (if any) and the date and type of the training event. It then asks the trainee to rate their confidence and competence across the 5 domains of the end of life care competences via the 27 Likert-scaled responses. Additionally, two narrative questions seek free text responses from the trainee on their reasons for attendance and expectations of the event.

\section{End of training section "Tool B"}

Administered at the end of the training event, usually at the event venue itself, the trainee re-rates their confidence and competence via the same 27 statements. They do so without sight of their pretraining responses. Additionally, narrative questions ask whether the training has met their expectations, and ask the trainee to articulate specific actions they plan to undertake as a consequence of the training. This question reflects emerging evidence on the value of action planning (or goal setting) within educational and behaviour change interventions.[29, 30]

\section{Optional follow up section "Tool C"}

Designed for postal administration weeks or months after training, this section repeats the 27 Likert statements then poses three new narrative questions which ask the trainee to report any impacts of training in relation to: (i) recognising dying; (ii) avoiding inappropriate hospital admissions; and (iii) initiating conversations about end of life. These questions were framed in relation to English national end of life care targets,[5] and quality standards.[23]

\section{Reliability}

Test retest reliability 
The convenience sample of 112 student nurses completed the Likert section of the questionnaire on two separate occasions one week apart. The overall total score at each time point correlated best, with a Pearson $r$ correlation of 0.84 . A score of 1 indicates a perfect correlation but scores of 0.7 or above are generally considered to be highly correlated.[31] Four of the five sub-scales also correlated highly. The score that correlated least well was 'overarching values and knowledge' (Pearson's $r$ of 0.56), indicative of a moderate to good correlation. These results in Table 3 suggest the tool has good test-retest reliability and that changes in score over time can be attributed to changes in self-assessed confidence and competence as opposed to the effect of repeat administration.

TABLE 3: Reliability test results: test-retest $(n=112)$

\begin{tabular}{|c|c|c|c|c|}
\hline Construct & $\begin{array}{l}\text { Mean average at } \\
\text { time } 1\end{array}$ & $\begin{array}{l}\text { Mean average at } \\
\text { time } 2\end{array}$ & Correlation value & $p$ value \\
\hline $\begin{array}{l}\text { Communication } \\
\text { skills }\end{array}$ & 20.920 (SD 3.448) & 21.667 (SD 3.084) & 0.759 & 0.000 \\
\hline $\begin{array}{l}\text { Assessment \& care } \\
\text { planning }\end{array}$ & 21.756 (SD 4.206) & 22.826 (SD 3.918) & 0.724 & 0.000 \\
\hline $\begin{array}{l}\text { Symptom } \\
\text { Management }\end{array}$ & 16.449 (SD 3.265) & 17.320 (SD 3.303) & 0.705 & 0.000 \\
\hline $\begin{array}{l}\text { Advance Care } \\
\text { Planning (ACP) }\end{array}$ & 13.949 (SD 2.701) & 14.455 (SD 2.460) & 0.669 & 0.000 \\
\hline $\begin{array}{l}\text { Overarching values } \\
\& \text { knowledge }\end{array}$ & 19.255 (SD 3.192) & 19.310 (SD 3.145) & 0.569 & 0.000 \\
\hline Overall totals & $\begin{array}{c}92.081(\mathrm{SD} \\
12.497)\end{array}$ & $\begin{array}{c}94.911 \text { (SD } \\
12.401)\end{array}$ & 0.840 & 0.000 \\
\hline
\end{tabular}

Table 4 provides the pre and post training scores for 1793 trainees who completed the assessment tool. In contrast to the test retest scores which showed minimal change, these scores showed that trainees overall self-perceived confidence and competence had increased on average by approximately 13 points (possible scores range from 27 to 135 ).

TABLE 4: Average pre and post training scores for respondents who had completed end of life care training $(n=1793)$

\begin{tabular}{llllc}
\hline Construct & $\begin{array}{l}\text { Pre training } \\
\text { mean average }\end{array}$ & $\begin{array}{l}\text { Post training } \\
\text { mean average }\end{array}$ & $\begin{array}{l}\text { Mean Change in } \\
\text { score }\end{array}$ & p value* \\
\hline $\begin{array}{l}\text { Communication } \\
\text { skills }\end{array}$ & 21.448 (SD 4.161) & 25.059 (SD 4.343) & 3.602 (SD 3.930) & 0.000 \\
$\begin{array}{l}\text { Assessment \& care } \\
\text { planning }\end{array}$ & 14.816 (SD 5.114) & 17.410 (SD 5.414) & 2.612 (SD 3.224) & 0.000 \\
\cline { 1 - 1 } & & & & \\
\end{tabular}




\begin{tabular}{|c|c|c|c|c|}
\hline $\begin{array}{l}\text { Symptom } \\
\text { Management }\end{array}$ & 16.192 (SD 4.199) & 19.237 (SD 4.440) & 3.077 (SD 3.395) & 0.000 \\
\hline $\begin{array}{l}\text { Advance Care } \\
\text { Planning (ACP) }\end{array}$ & 14.935 (SD 3.017) & 17.111 (SD 3.161) & 2.160 (SD 2.754) & 0.000 \\
\hline $\begin{array}{l}\text { Overarching values } \\
\& \text { knowledge }\end{array}$ & 19.751 (SD 3.611) & 21.483 (SD 3.952) & 1.749 (SD 2.996) & 0.000 \\
\hline Overall totals & $\begin{array}{c}91.695 \text { (SD } \\
20.894)\end{array}$ & $\begin{array}{c}104.915 \text { (SD } \\
24.781)\end{array}$ & $13.220(17.547)$ & 0.000 \\
\hline
\end{tabular}

*Wilcoxon signed rank test

\section{Internal consistency}

The internal consistency of responses was calculated for a total of 1793 questionnaires; all components had acceptable (>0.7) Cronbach's $\alpha$ values.[27] Taking into account that the sub-scales comprised a relatively low number of items, this indicates good reliability. These results indicate that within the five key components the questions successfully assess different aspects of the same underlying concept (see Table 5). Furthermore, the absence of extremely high correlations indicates that there were no redundant questions, i.e. items that were so similar that they simply asked the same question in marginally different ways.

TABLE 5: Reliability test results: internal consistency via Cronbach's $\alpha$ values using Pearson $r$

\begin{tabular}{lll}
\hline Component & Cronbach's $\boldsymbol{\alpha}$ & $\begin{array}{l}\text { No. of Likert } \\
\text { scale items }\end{array}$ \\
\hline Communications skills & 0.845 & 6 \\
$\begin{array}{l}\text { Assessment and care } \\
\text { planning }\end{array}$ & 0.863 & 7 \\
\hline $\begin{array}{l}\text { Symptom management } \\
\text { Advance care planning }\end{array}$ & 0.863 & 5 \\
\hline Values and knowledge & 0.823 & 4 \\
\hline
\end{tabular}

\section{7 items}

\section{Validity}

The first structured consultation was via a trainer feedback questionnaire completed during field work. This feedback yielded 23 completed responses from 16 trainers representing 10 organisations relating to 23 different training events (separate questionnaires were completed for each event). Trainer responses to the Likert-scaled statements are shown in Table 6. Their narrative responses 
indicated that overall trainers liked the format of EMET, that trainees were able to complete it, and that it fitted their training's content and learning outcomes.

TABLE 6: Field-testing trainers' questionnaire responses $(n=23)$

\begin{tabular}{lccc}
\hline & $\begin{array}{c}\text { Strongly agree/ } \\
\text { agree }\end{array}$ & Neutral & $\begin{array}{c}\text { Strongly } \\
\text { disagree/ } \\
\text { disagree }\end{array}$ \\
\hline $\begin{array}{l}\text { The guidance for use of the tool was } \\
\text { easy to follow }\end{array}$ & 21 & 2 & \\
\hline I liked the overall format of the tool & 22 & 1 & 1 \\
\hline $\begin{array}{l}\text { Trainees were able to complete the } \\
\text { pre and post training sections }\end{array}$ & 21 & 1 & 3 \\
\hline $\begin{array}{l}\text { I feel the tool adequately measured } \\
\text { the aims of this learning event }\end{array}$ & 19 & 1 & \\
\hline
\end{tabular}

The trainers' narrative comments provided insights on the EMET's positive and limiting features. Four trainers commented that it was time-consuming for students to complete, and one reported that some trainees rushed through the post-training section, particularly at the end of the day. One trainer thought the tool did not match the specific clinical content of their training event. One commented that trainees could not remember their pre-course expectations and thus could not accurately report on whether expectations were met. On the other hand, three trainers commented that the specific focus on end of life care was particularly useful, and that trainees' completion of the tool provided them with particularly valuable feedback for future training events.

The second structured consultation took the form of a three part workshop at the UK National Association of Palliative Care Educators (NAPCE) conference. In total 22 experienced end of life care trainers participated in the workshop. Group feedback and discussions were collated and the findings are summarised in Table 7.

TABLE 7: Comments about the tool from experienced end of life care trainers' workshop The experienced trainers' views on the tool's positive features

Comprehensively covers multiple end of life care topics

Fidelity to nationally recognised competences Inclusion of aspects of attitudes and beliefs 
Incorporating both confidence and competence is useful because for some more capable trainees, training may not change actual competences, but may impact upon their recognition of and confidence in applying their competences

The mixture of short Likert-scaled and longer free-text response elements allows for efficient coverage of multiple relevant domains, whilst also enabling collection of more detailed feedback Collects data on elements of training events that trainers see as important, and this contrasts with some standard feedback forms that ask about peripheral matters such as car parking and refreshments

Capacity to collect both brief responses on a wide range of end of life care competencies and longer free-text responses which could be used to modify and develop future training.

\section{The experienced trainers' views on possible limitations}

Will trainees' responses be valid? They might be motivated to rate themselves lower prior to training in order to allow 'room for improvement'

Might there be ceiling effects? If a trainee scores themselves highly pre-training, it is not possible to capture any change using the tool

Post-training score could be lower than pre-training one if the training helps a trainee to recognise what they do not know (i.e. if it helps them recognise need for greater confidence and competence). Whilst a trainer might regard this as a positive outcome, a manager or commissioner may not

Some terms used may be difficult for people with little experience in end of life care to understand

Some questions too long

The neutral 'neither agree nor disagree' response option may be unhelpful

Some courses may have a narrower topical focus than the EMET, so some questions may not be relevant

Overall, a large majority of the 38 trainers consulted during field-testing and at the conference workshop considered that the EMET measures what it sets out to measure and is relevant to a range of training events and trainees. Most also remarked that it was practical, flexible to different training events across a range of professional groups and easily administered.

A large majority of trainers reporting on their experiences of using the EMET in 23 training events indicated that they liked the format, that trainees were able to easily complete it, and that it was appropriate for the content of their training. A separate cohort of 22 experienced end of life care trainers consulted via a workshop appreciated its comprehensiveness, its congruence with a nationally defined competence framework, and its capacity to collect both brief responses on a wide range of end of life care competencies and longer free-text responses which could be used to modify and develop future training.

\section{DISCUSSION}

We developed the EMET to evaluate diverse end of life care training events in England after establishing there were no existing validated tools that were suitable for the wide range of events 
and trainees who participate in them. The validated tool provides a comprehensive approach for evaluating training in terms of changes in self-reported confidence and competence across five core areas, reflecting the domains of the English core competencies for end of life care.[19] The tool is suitable for use with a wide range of trainees across a spectrum of end of life care training events. Our small-scale evaluation of its test-retest reliability and a larger scale evaluation of its internal consistency, usability and validity yielded positive results.

The experienced trainers who participated in validity testing also commented on some drawbacks and limitations of the tool. Their responses suggest the EMET may be too lengthy for administration in training events lasting half a day or less. They raised concerns about possible ceiling effects; i.e. that it will not measure changes in trainees who report high levels of confidence and competence pre-training. We acknowledge that anecdotally we know that trainers varied in how effectively they were able to ensure how delegates completed the tool. Trainers also raised concerns about the validity of the trainees' responses. This latter concern is congruent with numerous empirical studies that have shown that self-report does not straightforwardly reflect actual skill. We know that in general, self-reports yield larger change scores than evaluation of actual performance.[8, 9] Indeed, it has long been recognised that knowledge about clinical matters is much more easy to assess than actual application of that knowledge to workplace performance.[32] Therefore, where resources allow, multiple assessments including actual workplace performance and patient outcomes should be used. These will potentially yield a more accurate understanding of training's impacts than can be gleaned from self-reports.[7, 32] However, in situations where resources are limited, assessment of the impacts of training courses upon trainees via their self-report, such as provided by the EMET, offers a feasible and economical means of measuring a limited aspect of training's impacts. Trainers, trainees, managers and commissioners should nevertheless be aware that that self-reports provide very limited insights into actual workplace behaviour change. The validated tool provides a baseline in recognising changes in confidence and competence as a starting point to be able to identify impacts of training on clinical practice. Overall the validated tool fills a recognised gap currently evident in evaluating end of life care training events.

Final version 6 was produced on the basis of reliability and validity testing. This version of EMET is freely available and can be downloaded from the Nottingham Centre for the Advancement of Supportive, Palliative and End of Life Care, University of Nottingham (NCARE) http://nottingham.ac.uk/research/groups/srcc/postgrad-course.aspx. It is currently in use in a range of events internationally in the context of a continued drive to improve end of life care delivery. Our 
work in developing and validating EMET adds to the understanding of how training can impact on workforce ability to meet patient outcomes in end of life care.

\section{Strengths and Limitations}

We designed an acceptable and useable tool, conducting preliminary testing of the EMET's validity and reliability. Limitations of the test-retest reliability include the comparatively small and homogenous sample and the brief time period between administrations. Whilst this reduced the likelihood of confounding factors influencing the second test, it remains conceivable that it was insufficient time for any effects of completing the first test to have dissipated. We acknowledge the comparatively low reliability score for overarching values and knowledge and suggest that this dimension might be particularly sensitive to repeat administration. Further exploration of the factors affecting the overarching values and knowledge score would be valuable. Strengths of this study include the comparatively large data set that was used to test internal consistency and the breadth and range of individuals who contributed to the assessments of validity over a period of time.

The EMET was designed in the context of policy and practice in England, and whilst its comprehensive coverage relates to end of life care delivery nationally, we suggest that it could be usefully applied in other countries. Such application should ideally be accompanied by testing of reliability and validity across different national and cultural contexts.

\section{CONCLUSION}

We advocate use of this freely available validated evaluation tool of self-reported confidence and competence (Supplementary File 2), to assess impacts of end of life care training and to gather feedback on training events. Where feasible, additional observational assessment of performance will provide more direct evaluation of training's impact on practice and quality of service provision within the context of end of life.

\section{ETHICS}

None required. All trainees and facilitators were informed that data would be used as part of the tool development and testing.

\section{ACKNOWLEDGEMENTS}


The EMET project was initially funded by the East Midlands Strategic Health Authority and the National End of Life Care Programme, UK up to 2013.

THE EMET PROJECT TEAM comprised;

Debra Broadhurst, LOROS Hospice Leicester, early questionnaire design

Professor Jane Seymour, Sue Ryder Care Centre for the Study of Supportive, Palliative and End of Life Care, project support

Gavin Narayanasamy, Melanie Narayanasamy and Sarah Todd, data input and analysis

Dr Anthony Arthur, early advice on statistics methods

Contributorship statement

BW, SW, CF were responsible for the project planning

BW and SW were responsible for conduct of the study

$\mathrm{BW}, \mathrm{SW}, \mathrm{LB}, \mathrm{CF}, \mathrm{RP}$ contributed to the reporting and discussion

BW has overall responsibility for the content

Competing Interest: None declared.

Licence for Publication

The Corresponding Author has the right to grant on behalf of all authors and does grant on behalf of all authors, an exclusive licence (or non exclusive for government employees) on a worldwide basis to the BMJ Publishing Group Ltd to permit this article (if accepted) to be published in BMJ Supportive and Palliative Care and any other BMJPGL products and sublicences such use and exploit all subsidiary rights, as set out in our licence (http://group.bmi.com/products/journals/instructions-forauthors/licence-forms).

\section{REFERENCES}

1. Leadership Alliance for Care of Dying People. One chance to get it right: Improving people's experience of care in the last few days and hours of life. London: NHS England 2014

2. The Scottish Government. Strategice Framework for Action on Palliative and End of Life Care 2016-2021. Glasgow: NHS Scotland 2015

3. National Consensus Project for Quality Palliative Care. Clinical Practice Guidelines for Quality Palliative Care: 3rd Edition 2013 http://www.nationalconsensusproject.org (accessed 12.10.2015)

4. Gamondi C, Larkin P, Payne S. Core competencies in palliative care: an EAPC White Paper on palliative care education - part 1. Eur J Palliat Care 2013;20:86-139.

5. Department of Health. End of Life Care Strategy: Promoting High Quality Care for All Adults at the End of Life. Third annual report. London: Department of Health 2011. 
6. Hullsman RRW, Winnubust J, Bensing J. Teaching clinically experienced physicians communication skills. A review of evaluation studies. BMC Med Educ 1999;33:655-68.

7. Parry R. Are interventions to enhance communication performance in allied health professionals effective, and how should they be delivered? Direct and indirect evidence. Patient Educ Couns 2008;73:186-95.

8. Dunning DHC, Suls JM. Flawed self-assessment: Implications for Health, Education and the Workplace. Psychol Sci Public Interest 2004;5:69-106.

9. Davis DMP, Fordis M, Harrison RV et al. Accuracy of Physician Self-assessment compared with Observed Measures of Competence. JAMA 2006;296:1094-102.

10. Frey R, Gott $M$, Banfield R, et al. What questionnaires exist to measure the perceived competence of generalists in palliative care provision? A critical literature review. $B M J$ Support Palliat Care 2011;1:19-32.

11. Slatten K, Hatlevik O, Fagerstrom L. Validation of a new instrument for self-assessment of nurses' core competencies in palliative care. Nurs Res Pract 2014; http://dx.doi.org/10.1155/2014/615498 (accessed 12.10.2015)

12. Shih $\mathrm{CY}, \mathrm{Hu}$ WY, Lee LT et al. Effect of a compassion-focused training program in palliative care education for medical students. Am J Hosp Palliat Care 2013;30:114-20.

13. Harris DHL, Keat N. Sustainable Practice Improvements: Impact of the Comprehensive Advanced Palliative Care Education (CAPCE) Program. J Palliat Care 2007;23:262-72.

14. McClement SCD, Dean R. Evaluation of Education in Palliative Care: Determining the Effects on Nurses' Knowledge and Attitudes. J Palliat Care 2005;21:44-8.

15. Otis-Green S, Ferrell B, Spolum M et al. An overview of the ACE Project- Advocating for Clinical Excellence: transdisciplinary palliative care education. J Cancer Educ 2009;24:120-6.

16. Bandura A. Self-efficacy: Toward an Unifying theory of Behavioral Change. Psychol Rev 1977;84:191-215.

17. Gamondi, C, Larkin, P, Payne, S. Core competencies in palliative care: an EAPC white paper on palliative care education - part 2. Eur J Palliat Care 2013;20:140-45.

18. Skills for Health. Common core principles and competences for social care and health workers working with adults at the end of life. Leeds: Skills for Care 2014.

19. National End of Life Care Programme, Skills for Health, Skills for Care. Core competences for end of life care: Training for health and social care staff. London: Department of Health 2009.

20. Faull C, Nicholson A, Black F. Handbook of Palliative Care. 3rd ed. Hoboken, NJ: Wiley Blackwell 2012.

21. Feathers L, DeCaestecker S, Norrie P et al. Developing Skills in Communication in End of Life Care: Evaluation of a 3 Day Pilot Course for Core Medical Training. BMJ Support Palliat Care 2014;4(Suppl 1):A38

22. Howard $\mathrm{P}$, Whittaker B. (nee Chady) Placement learning in cancer and palliative care nursing: A guide for students in practice. Edinburgh: Baillière Tindall/Elsevier 2012.

23. National Institute for Health and Care Excellence. End of life care for adults: NICE quality standard 13 2011. https://www.nice.org.uk/guidance/qs13 (accessed 12.10.2015)

24. Wade D. Reasons for Assessing: Measurement in Neurological Rahabilitation. Oxford: Oxford Medical 1992. 
25. Bausewein C, Daveson B, Benalia H et al. Outcome Measurement in Pallative Care: The essentials. PRISMA 2011. http://www.eapcnet.eu/LinkClick.aspx?fileticket=T62WTgTHtU\%3D\&tabid=1577 (accessed 12.10.2015)

26. Field A, Hole GJ. How to design and report experiments. London: Sage 2003.

27. De Vaus D. Surveys in Social Research. 6th Edition ed. New York: Routledge 2013.

28. Elo $S$, Kyngas $H$. The qualitative content analysis process. J Adv Nurs 2008 April;62:107-15.

29. Cowan CA, Goldman EF, Hook M. Flexible and inexpensive: Improving learning transfer and program evaluation through participant action plans. Perf Improv 2010;49:18-25.

30. Battersby M, Michael VK, Schaefer J et al. Twelve Evidence-Based Principles for Implementing Self-Management Support in Primary Care. Jt Comm J Qual Patient Saf

31. Hinkle DE, Wiersma W, Jurs SG. Applied Statistics for the Behavioural Sciences. 5th ed. Boston: Houghton Mifflin 2003

32. Wass V, Van der Vleuten C, Shatzer J et al. Assessment of clinical competence. Lancet 2001;357:945-9.

\section{LIST OF TABLES}

TABLE 1: The English Department of Health Core Competences for End of Life Care

TABLE 2: Training events and trainees using the tool

TABLE 3: Reliability test results: test-retest $(n=112)$

TABLE 4: Average pre and post training scores for respondents who had completed end of life care training ( $n=1793)$

TABLE 5: Reliability test results: internal consistency via Cronbach's $\alpha$ values using Pearson $r$

TABLE 6: Field-testing trainers' questionnaire responses $(n=23)$

TABLE 7: Comments about the tool from experienced end of life care trainers' workshop

\section{LIST OF FIGURES}

FIGURE 1: Process of tool development 